\title{
PRODUCCIÓN DE ETANOL POR DIGESTIÓN DE RESIDUOS LIGNOCELULÓSICOS DEBIDO A HONGOS DEL SUELO AGRÍCOLA DE LA CIUDAD DE LIMA
}

\author{
E'THANOL PRODUCTION BY DIGESTION OF LIGNOCELLULOSIC \\ WASTE DUE TO AGRICULTURAL SOIL FUNGI OF LIMA CITY \\ (iD) Leslie Giovana Delgado Olivares ${ }^{1 *}$, (D) Ramsés Salas Asencios ${ }^{1}$ \\ rsalas@unfv.edu.pe; rsalas@unfv.edu.pe \\ ${ }^{1}$ Universidad Nacional Federico Villarreal, Lima, Perú.
}

*Correspondencia: Leslie Giovana Delgado Olivares. Email: rsalas@unfv.edu.pe

Recibido: 06.12.2020 | Aprobado: 23.12.2020

\section{RESUMEN}

Se aislaron cepas de hongos con actividad celulásica desde muestras de suelo agrícola. Los hongos aislados pertenecieron a los géneros Aspergillus, Penicillium y Fusarium, presentando diferentes rendimientos en la producción de glucosa. Los hongos con mayor capacidad de digestión de celulosa pertenecieron al género Penicillium y Fusarium, permitiendo un mayor rendimiento en cuanto a producción de etanol a partir de la fermentación del producto de digestión con levadura de panadería.

Palabras clave: Actividad celulásica, bioetanol, penicillium, fusarium, aspergillus.

\section{ABSTRACT}

Strains of fungi with celulase activity were isolated of agricultural soil samples. Isolated fungi belonged to the genera Aspergillus, Penicillium and Fusarium, showing different yields of etanol production. Fungi with the highest cellulase activity were mainly of the genus Penicillium and Fusarium, allowing a higher yield in terms of etanol production from the fermentation of the digestion product with baker's yeast.

Keywords: Cellulase activiy, bioethanol, penicillium, fusarium, aspergillus. 


\section{INTRODUCCIÓN}

La lignocelulosa es una gran fuente natural de carbono que es aprovechada por diversos grupos de organismos que han desarrollado diversos mecanismos de digestión, principalmente a través de enzimas que actúan de modo complementario y sinergístico. Dentro de este grupo de enzimas sobresalen las glucósido-hidrolasas, las cuales cortan los enlaces glucosídicos de la celulosa y la hemicelulosa. Estas actividades enzimáticas son acompañadas por ejemplo por las polisacárido-esterasas, que remueven ésteres de metilo, acetilo y fenólicos, permitiendo así que las hidrolasas actúen básicamente sólo sobre hemicelulosa. En el caso de los hongos filamentosos celulásicos, las hidrolasas que actúan son parte de la familia 7 de glucósido-hidrolasas, potentes celobiohidrolasas (Cragg et al., 2015).

Existen muchas especies de hongos filamentosos que poseen actividad lignocelulásica debido a su naturaleza saprofítica, por lo que han sido utilizados de manera industrial para degradar agentes contaminantes como el papel, o para el procesamiento de ciertos productos como el café (Sivaramanan, 2014), siendo muy sugestivo el aislamiento e identificación de estos hongos a partir de diferentes tipos de suelos asociados a la presencia de residuos lignocelulósicos. Sari et al. (2017) aislaron y analizaron la actividad celulásica de hongos presentes en la hojarasca de la palmera Salacca zalacca, identificando microorganismos pertenecientes a los géneros Penicillium, Aspergillus, Paecilomyces y Thielaviopsis, que son considerados como candidatos para producción industrial de celulasa. Sivaramanan (2014) aisló 21 hongos a partir de aserrín y de tres tipos de suelo (de jardín, de playa y fango) además de hojarascas. Identificó varias cepas con alta capacidad celulásica utilizando el método de digestión de papel filtro y cuantificación de glucosa por el método DNS. El autor identificó a Helminthosporium sp. como la cepa con mayor actividad celulásica, con una sacarificación del 3.8\%. La segunda cepa con mayor actividad celulásica fue identificada como perteneciente al género Cladosporium. Doolotkeldieva y Bobuseva (2011) aislaron cultivos silvestres de hongos provenientes de diversas regiones de Kyrgysztan (Turquía) y analizaron su actividad celulásica a partir de salvado de trigo, cáscara de remolacha y residuos de semilla de algodón, identificando una cepa de Penicillium y otra de Trichoderma lignorum con alta capacidad productora de glucosa reducida. Los autores recomendaron utilizar ambas cepas para producción de biomasa útil para fermentación a partir de desechos agrícolas. Guzmán et al. (2014) aislaron, seleccionaron y caracterizaron hongos celulásicos a partir de muestras de cinco tipos de suelo en Manabí-Ecuador. Estos autores identificaron 48 hongos, utilizando a Pleurotus ostreatus como control debido a su comprobada actividad celulasa. La mayoría de hongos celulásicos fueron aislados a partir de suelos agrícolas convencionales, pero el que tuvo mayor actividad enzimática provino de un aislado a partir de materia orgánica, creciendo en fase logarítimica hasta las 96 horas además de tener actividad amilolítica y pectinolítica.

En la actualidad, la humanidad se encuentra enfocada a la búsqueda de fuentes energéticas alternativas a los combustibles fósiles, como los llamados biocombustibles, siendo el bioetanol el más producido, principalmente por Estados Unidos y Brasil, utilizado como combustible puro o en combinación con gasolina (Branco et al., 2019). El bioetanol puede ser generado a partir de subproductos derivados de la industria agrícola, como por ejemplo los residuos lignocelulósicos (Sánchez et al., 2010). Matsakas y 
Christakoupoulos (2015) obtuvieron etanol a partir de la fermentación de material celulósico de residuos alimenticios digerido por acción del hongo termofílico Myceliphthora thermophila, con un rendimiento de $0.92 \mathrm{~g} /$ L.h. Por otro lado, Sato et al. (2010) purificaron tres isoenzimas de tipo xilanasa a partir de un cultivo en estado sólido de Aspergillus oryzae por cromatografía y midieron la estabilidad de su actividad enzimática en presencia de alcohol durante la producción de sake, una bebida alcohólica tradicional japonesa. Los autores lograron identificar una de estas enzimas con actividad estable aún en presencia de etanol al $80 \%$ por 30 minutos, mostrando que se puede conseguir digestión fúngica de celulosa aún incluso cuando en el mismo medio se está produciendo la fermentación alcohólica.

El presente trabajo muestra actividad celulásica de hongos aislados de suelo agrícola con el fin de generar etanol a partir de la digestión de hojas secas.

\section{MATERIAL Y MÉTODOS}

Obtención de las cepas de hongos lignocelulósicos: Se tomaron muestras de 200 g. de suelo de los jardines de la Facultad de Ciencias Naturales y Matemática en el distrito de El Agustino, en Lima (Perú), suelo previamente de uso agrícola y que aún presenta riqueza nutritiva para el desarrollo de diversas especies de plantas. De cada una de estas muestras se tomaron $50 \mathrm{~g}$ que fueron diluidos en $100 \mathrm{~mL}$ de agua destilada. Las muestras fueron dejadas en reposo por 20 minutos y luego se tomó $1 \mathrm{~mL}$ del sobrenadante de cada muestra para realizar un cultivo por dispersión en una placa Petri conteniendo Agar Papa Dextrosa (APD) utilizando un asa de Drigalsky. Se incubaron las placas por 4 días, evaluando la formación de colonias de hongos, y luego se procedió a repicar cada colonia por separado en placas con agar APD. Se realizó un microcultivo de cada colonia aislada según Procop et al. (2017) con el fin de determinar el género al que pertenecen. El microcultivo se realizó cerca de un mechero Bunsen, dentro de una placa Petri, en la cual se colocaron 2 varillas esterilizadas sirviendo como soporte. Se usó una lámina portaobjeto desinfectada con alcohol fue colocada encima de las varillas. Sobre esta lámina se colocó un trozo cuadrado de agar APD de $1 \mathrm{~cm}$ en cada lado y encima de este cuadrado de agar se colocó una lámina cubreobjetos totalmente esterilizada. Con ayuda de un asa de siembra en ángulo, se cogió un poco de micelio de cada hongo aislado y se hizo una siembra por puntura a la mitad de cada lado del cuadrado de agar. Se tapó la placa Petri colocando dentro un pedazo de algodón humedecido en agua. Este cultivo se dejó a temperatura ambiente por 1 semana aproximadamente. Luego se retiró el cuadrado de agar y a las láminas porta y cubreobjetos se le agregaron una gota de Azul de Lactofenol para poder realizar la observación al microscopio a $400 \mathrm{X}$.

Evaluación de la capacidad de digestión de los residuos lignocelulósicos: Se prepararon digestores a partir de botellas de plástico (Figura 1), dentro de los cuales se colocaron $20 \mathrm{~g}$. de hojas de árboles totalmente secas y pulverizadas (Kurambhatti et al., 2018). Este polvo de hojas fue resuspendido con $240 \mathrm{~mL}$ de agua destilada y se inoculó con un raspado de hifas de 3 colonias aisladas utilizando un asa de siembra.

La determinación de la actividad digestiva de los residuos lignocelulósicos se realizó considerando la medición de glucosa liberada luego de un tiempo de incubación. Para ello, se tomaron muestras de $5 \mathrm{ml}$ de cada digestor a las 3 semanas y se midió la concentración 
de azúcares libres de cada muestra con el reactivo DNS (Hussain et al., 2012), preparando una curva estándar con solución de glucosa pura.

\section{Figura 1}

Esquema del frasco digestor utilizado en el experimento.

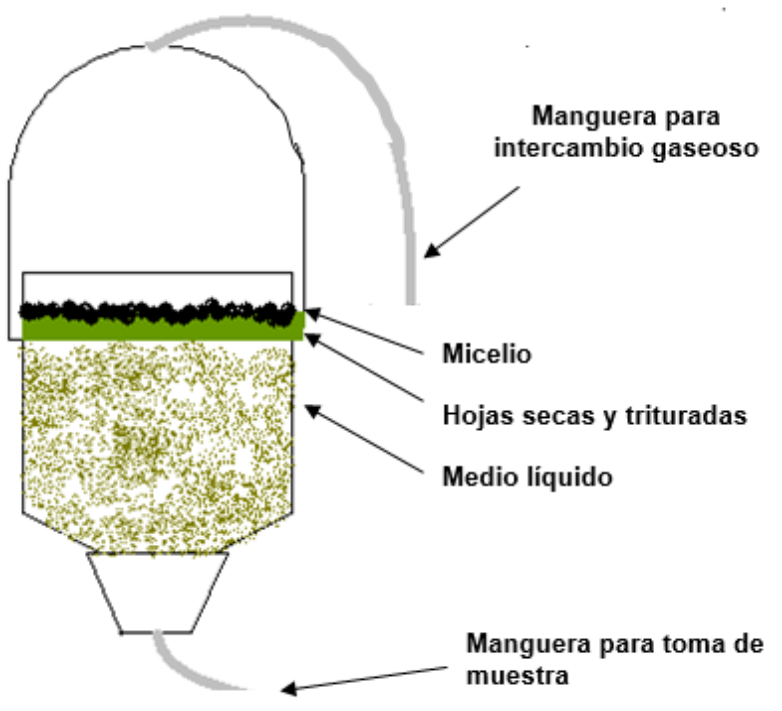

Digestión de las hojas y producción de etanol: Se colocaron en cada digestor $20 \mathrm{~g}$ de hoja en polvo y $240 \mathrm{~mL}$ de agua y luego en la capa superficial generada se colocó una porción del micelio de cada hongo identificado, dejando que se realice una digestión por 4 semanas. Luego de este tiempo, el contenido de cada digestor fue filtrado según Drissen et al. (2009), y del filtrado se tomaron $5 \mathrm{~mL}$ para medir la cantidad de azúcar liberada y al resto del volumen de digestión se le agregó $10 \mathrm{~mL}$ de una suspensión de levadura comercial (Saccharomyces cerevisiae) en polvo al 30\% (p/p). Se colocó todo el sistema en frascos de vidrio color caramelo llenos por completo y se incubó por 2 semanas a $30^{\circ} \mathrm{C}$. Posteriormente, se midió el grado de alcohol producido durante la fermentación con un alcoholímetro.

\section{RESULTADOS}

Las cepas aisladas del suelo fueron analizadas por observación de sus características morfológicas tanto en el macro como en el microcultivo. La identificación taxonómica a nivel de género se realizó con ayuda de las claves descriptivas morfológicas del Manual de procedimientos y técnicas de laboratorio para la identificación de los principales hongos oportunistas causantes de micosis humana (INS y MINSA, 2007) y la Clave dicotómica para la identificación de hongos aislados de la Sociedad Española de Microbiología (2014), sirviendo como claves descriptivas morfológicas de la colonia y de la micromorfología de cada hongo filamentoso, ambas con sus respectivas imágenes macro y microscópicas (Figura 2). Los hongos aislados pertenecieron a los géneros Aspergillus, Penicillium y Fusarium. 


\section{Figura 2}

Características a nivel de macrocultivo y microcultivo de cepas aisladas de Aspergillus sp. (A) Fusarium sp. (B) Aspergillus sp. (C) Aspergillus sp. (D) y Penicillium sp. (E).

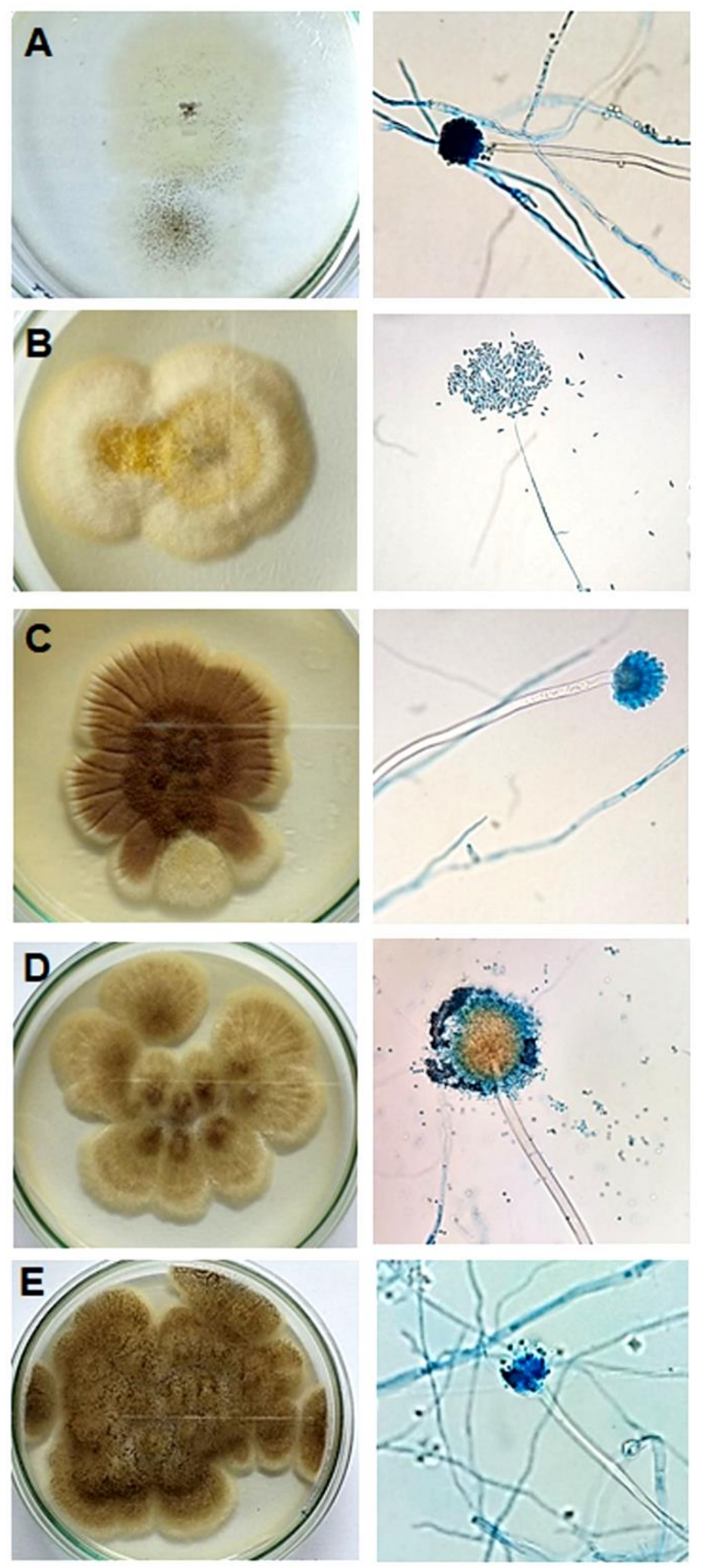

La Figura 3 muestra los resultados de una primera digestión de residuos de hojas secas (hojarasca) pulverizadas. La digestión se realizó por 3 semanas y se puede observar 
diferencias en cuanto a la cantidad de azúcares reductores según la especie de hongo, observándose una mayor liberación de glucosa por una de las cepas de Aspergillus spp.

\section{Figura 3}

Liberación de azúcares reductores (glucosa) de 4 cepas aisladas y mostradas en la Figura 2, luego de una digestión por 3 semanas de hojas pulverizadas y secas.

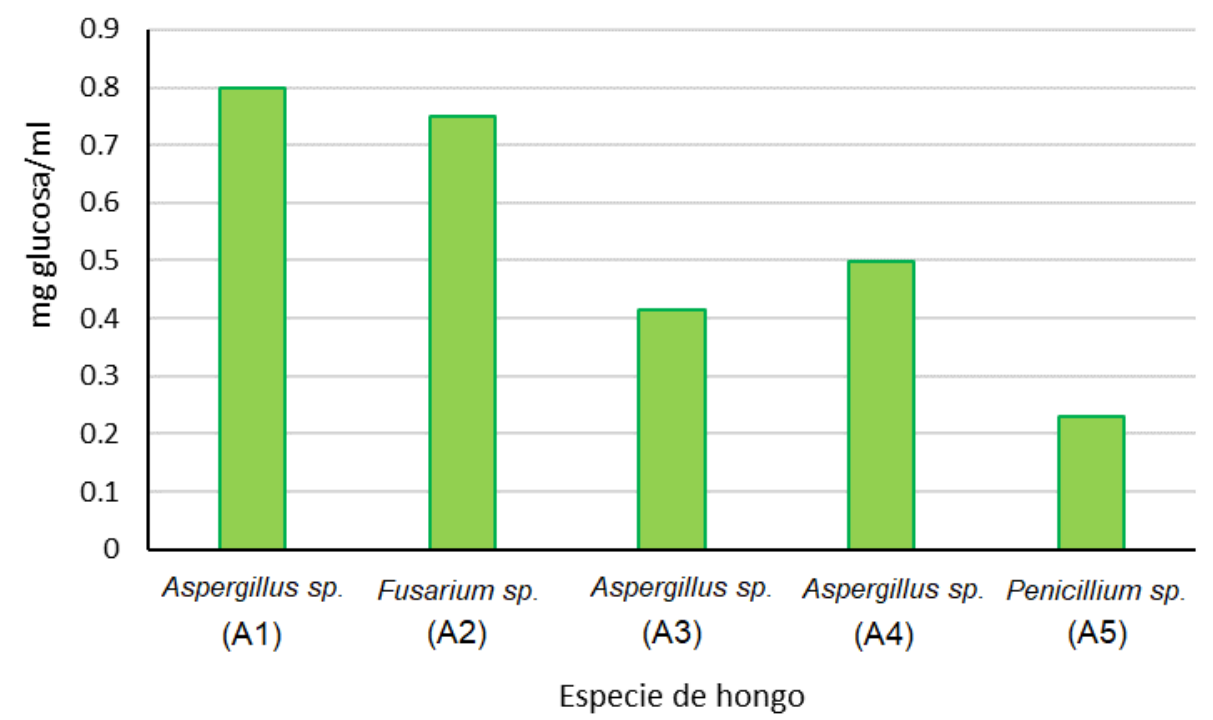

La Figura 4 muestra la cantidad de azúcar liberada en cada botella en función del tiempo de digestión (2 a 4 semanas). Se puede mostrar que hay un incremento marcado de producción de azúcares reductores a la cuarta semana de digestión en las cepas A1 (Aspergillus sp.), A2 (Fusarium sp.) y A3 (Aspergillus sp.). Los mismos resultados se pueden ver en la Tabla 1, pero en términos de rendimiento (mg de azúcar por litro de solución y por gramo de hoja seca).

\section{Figura 4}

Liberación de azúcares reductores (glucosa) de las cepas aisladas a diferentes tiempos de digestión. A1: Aspergillus sp., A2: Fusarium sp., A3: Aspergillus sp., A4: Aspergillus sp., A5: Penicillium sp.

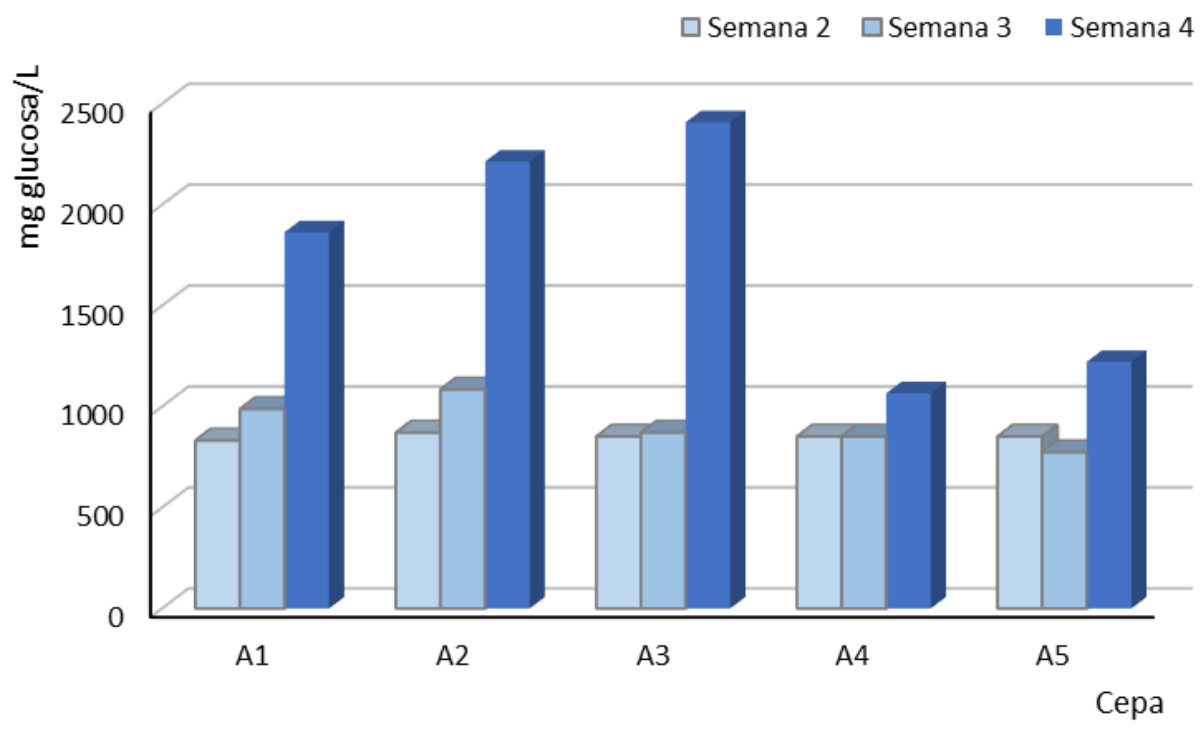




\section{Tabla 1}

Rendimiento en mg de glucosa por litro de medio y por gramo de hoja seca de las cepas aisladas y a diferentes tiempos de digestion. A1: Aspergillus sp., A2: Fusarium sp., A3: Aspergillus sp., A4: Aspergillus sp., A5: Penicillium sp.

\begin{tabular}{llll}
\hline Muestra & Semana 2 & Semana 3 & Semana 4 \\
\hline A1 & 740.94 & 9600.00 & 1948.99 \\
A2 & 2351.68 & 8995.97 & 2955.70 \\
A3 & 539.60 & 4969.13 & 6177.18 \\
A4 & 1949.00 & 5975.84 & 869.80 \\
A5 & 338.26 & 2754.36 & 1143.62 \\
\hline
\end{tabular}

El grado de alcohol se midió a la semana después del inóculo con la levadura Saccharomyces cerevisiae. Los fermentadores que produjeron mayor grado alcohólico fue el que contenía las cepas A1 (Aspergillus sp.) con 1.5 grados, seguido del fermentador A3 (Aspergillus sp.) con 1 grado y finalmente A4 (Aspergillus sp.) con 0.8 grados. Al multiplicar estos valores de alcohol con el volumen de cada digerido, se obtuvo el rendimiento de alcohol por litro de digerido celulásico (Tabla 2).

\section{Tabla 2}

Rendimiento de alcohol por litro de digerido celulásico para 3 cepas de Aspergillus sp.

\begin{tabular}{lll}
\hline Cepa & Grado alcohólico & Rendimiento \\
\hline A1 & 1.5 & 6.250 \\
A3 & 1 & 4.167 \\
A4 & 0.8 & 3.333 \\
\hline
\end{tabular}

\section{DISCUSIÓN}

En el presente trabajo se utilizaron hojas secas caídas naturalmente (hojarasca) de diferentes árboles dentro del predio de la Facultad de Ciencias Naturales y Matemática. Los resultados muestran que las hojas secas y pulverizadas fueron un buen sustrato para la digestión por parte de los hongos celulásicos. Oliveira et al. (2006) emplearon cascarilla de arroz como sustrato y Mamma et al. (2008) emplearon distintos cultivos fúngicos para la hidrólisis de cáscaras de naranjas secas a través de una actividad multienzimática (xilanolítica, celulítica y pectinolítica). En vista que el sustrato de digestión usado estaba compuesto por hojas secas y pulverizadas, se considera que en el presente trabajo se obtuvo principalmente actividad celulásica y que el azúcar reductor liberado fue glucosa.

Respecto a los hongos filamentosos que fueron aislados, fueron identificados como pertenecientes a los géneros Aspergillus, Fusarium y Penicillium. Esos resultados concuerdan con los de Ekundayo y Juwon (2015), quienes identificaron hongos filamentosos con actividad lignocelulásica dentro de los géneros Aspergillus, Mucor, Penicillium, Rhizopus y otros a partir del suelo de aserraderos. Priyanka et al. (2017) también aislaron e identificaron hongos eficientemente productores de celulasa dentro de los géneros Aspergillus, Fusarium, Penicillium, Trichoderma y Chaetonium, entre otros.

Los hongos celulásicos fueron aislados en el presente trabajo a partir de suelo de tipo agrícola, al igual que Guzmán et al. (2014), Rodríguez-Guerra et al. (2012) y Ortiz y 
Uribe (2011), aunque también han sido aislados a partir de suelos con hojarascas (Nandana et al., 2013), compost (Mikán y Castellanos, 2004), paja de moringa (VásquezMontoya et al., 2020) y aserrín (Ekundayo y Juwon, 2015).

Los resultados mostrados en la Tabla 3 señalan al género Aspergillus como el que se puede usar para obtener un mayor rendimiento en la producción de etanol. De esta forma, se obtuvieron rendimientos entre 6.250 grados/L, y 3.333 grados/L. Drissen et al., (2009), utilizando levadura comercial (Saccharomyces cerevisiae) obtuvieron un rendimiento de 0.441 $\mathrm{g} / \mathrm{g}$ de glucosa en un sistema simultáneo de sacarificación y fermentación, y de $0.35 \mathrm{~g} / \mathrm{g}$ de glucosa en un sistema de hidrólisis separada de fermentación.

La producción de bioetanol de segunda generación a partir de material lignocelulósico, presenta ventajas económicas, ambientales y estratégicas, debido a que se puede producir a gran escala para ser utilizado en la elaboración de productos químicos o en la producción de biocombustible (Kim y Dale, 2004; Chandel y Singh, 2011). El bioetanol, usado como combustible o potenciador de gasolina, es completamente renovable en la naturaleza; ya que, al quemarlo, el dióxido de carbono que libera es reciclado y retorna a las plantas, debido a que estas lo utilizan para sintetizar celulosa durante la fotosíntesis. En comparación con los combustibles fósiles, el etanol reduce emisiones de efector invernadero en un 12\% (Castro-Martinez et al., 2012; Chandel y Singh, 2011).

\section{REFERENCIAS BIBLIOGRÁFICAS}

Branco, R.H.R., Serafim, L.S. y Xavier, A.M.R.B. (2019). Second Generation Bioethanol Production: On the Use of Pulp and Paper Industry Wastes as Feedstock. Fermentation, 5, 4; doi:10.3390/fermentation5010004.

Castro-Martínez C., Beltrán-Arredondo L.I. y Ortiz-Ojeda J.C. (2012). Producción de biodiesel y bioetanol: ¿una alternativa sustentable a la crisis energética? Ra Ximbai, $8(3), 93-100$.

Chandel, A.K. y Singh, O.V. (2011). Weedy lignocellulosic feedstock and microbial metabolic engineering: advancing the generation of 'Biofuel'. Appl Microbiol Biotechnol, 89, 1289-1303. doi: 10.1007/s00253-010-3057-6

Cragg S.M., Beckham G.T., Bruce N.C., Bugg T.D.H., Distel D.L., Dupree P., Etxabe A.G., Goodell B.S., Jellison J., McGeehan J.E., McQueen-Mason S.J., Schnorr K., Walton P.H., Watts J.E.M. y Zimmer M. (2015). Lignocellulose degradation mechanisms across the Tree of Life. Current Opinion in Chemical Biology, 29, 108 119. http://dx.doi.org/10.1016/j.cbpa.2015.10.018.

Doolotkeldieva T.D. y Bobusheva S.T. (2011). Screening of Wild-Type Fungal Isolates for Cellulolytic Activity. Microbiology Insights, 4, 1 - 10. https://journals.sagepub.com/doi/pdf/10.4137/MBI.S6418.

Drissen R.E.T.R.H., Maas W., Tramper, J., y Beeftink, H.H. (2009). Modelling ethanol production from cellulose: separate hydrolysis and fermentation versus simultaneous saccharification and fermentation. Biocatalysis and Biotransformation, 27(1), 27 - 35. https://doi.org/10.1080/10242420802564358. 
Ekundayo, T. y Juwon, A. (2015). Isolation and Identification of Cellulytic Fungi from Agrowastes and Sawmill Soils. British Biotechnology Journal, 7, 147 - 159. DOI: 10.9734/BBJ/2015/17575.

Guzmán A.M., Zambrano D.E., Rondón A.J., Laurencio M., Pérez M., León R. y Rivera R. (2014). Aislamiento, selección y caracterización de hongos celulásicos a partir de muestras de suelo en Manabí-Ecuador. Revista de la Facultad de Ciencias Agrarias de la Universidad de Cuyo, 46(2), 177 - 189. http://www.redalyc.org/articulo. oa?id $=382837658004$.

Hussain A., Shrivastav A., Jain S.K., Baghel R.K., Rani S. y Agrawal M.K. (2012). Cellulolytic Enzymatic Activity of Soft Rot Filamentous Fungi Paecilomyces variotii. Advances in Bioresearch, 3(3), 10 - 17.

INS y MINSA. (2007). Manual de procedimientos y técnicas de laboratorio para la identificación de los principales hongos oportunistas causantes de micosis humana. No 44. Lima, Perú.

Kim, S. y Dale, B.E. (2004). Global potential bioethanol production from wasted crops and crop residues. Biomass and Bioenergy, 26, $361-375$. https://doi.org/10.1016/j.biombioe.2003.08.002.

Kurambhatti, C.V., Kumar, D., Rausch, K.D., Tumbleson, M.E. y Singh, V. (2018). Ethanol Production from Corn Fiber Separated after Liquefaction in the Dry Grind Process. Energies, 11, 2921; doi:10.3390/en11112921.

Matsakas, L. y Christakopoulos, P. (2015). Ethanol Production from Enzymatically Treated Dried Food Waste Using Enzymes Produced On-Site. Sustainability, 7, 1446-1458. DOI:10.3390/su7021446.

Mamma, D., Kourtoglou, E., y Christakopoulos, P. (2008). Fungal multienzyme production on industrial by-products of the citrus-processing industry. Bioresource Technology, 99, 2373-2383. DOI:10.1016/j.biortech.2007.05.018.

Mikán, J. y Castellanos, E. (2004). Screening para el aislamiento y caracterización de microorganismos y enzimas potencialmente útiles para la degradación de celulosas y hemicelulosas. Revista Colombiana de Biotecnología, 6 (1), 58-71.

Nandana, G., Sridevi, A. y Narasimha, G. (2013). Screening and production of cellulase by fungal culture isolated from soil contaminated with cattle dung. Biotechnology India (BTAIJ), 7(3), $117-120$.

Oliveira, L.A., Porto, L.F.A., y Tambourgi, E.B. (2006). Production of xylanase and protease by Penicillium janthinellum CRC 87M-115 from diff erent agricultural wastes. Bioresource Technology, 97(6), 862-867. DOI:10.1016/j.biortech.2005.04.017.

Ortiz, M. y Uribe, D. (2010). Determinación de la actividad lignocelulásica en sustrato natural de aislamientos fúngicos obtenidos de sabanas de pastoreo y de bosque secundario de sabana inundable tropical. Ciencias del Suelo, 28 (2), 169-180.

Priyanka P., Yuvraj C, Farha S. y Aranganathan V. (2017). Isolation of cellulose degrading fungi from soil and optimization for cellulase production using Carboxy Methyl 
Cellulose. International Journal Of Life Science \& Pharma Research, 7(1), L-56 - L-60. http://www.ijlpr.com/admin/php/uploads/312_pdf.pdf.

Procop, G.W., Church, D.L., Hall, G.S., Janda, W.M., Koneman, E.W., Schreckenberger, P.C., y Woods, G.L. (2017). Koneman. Diagnóstico microbiológico, $7^{\mathrm{a}}$ edición. Buenos Aires Editorial Médica Panamericana.

Rodríguez-Guerra, A, Soria, C.A., Barnes, C.W., Ordóñez, M.E. y Salazar, A. (2012). Identificación y evaluación de algunos hongos con actividad celulásica aislados en Ecuador. Revista Ecuatoriana de Medicina y Ciencias Biológicas, 33(1), 65. DOI: 10.26807/remcb.v33i1-2.224

Sánchez A.M., Gutiérrez Morales A.I., Muñoz Hernández J.A. y Rivera Barrero C.A. (2010). Producción de bioetanol a partir de subproductos agroindustriales lignocelulósicos. Revista Tumbaga, 1(5), 61 - 91.

Sari S.L.A. Setyaningsih R. y Wibowo N.F.A. (2017). Isolation and screening of cellulolytic fungi from Salacca zalacca leaf litter. Biodiversitas, 18(3), 1282 - 1288. DOI:10.13057/biodiv/d180355.

Sato Y., Fukuda Y., Zhou Y. y Mikami S. (2010). Contribution of ethanol-tolerant xylanase G2 from Aspergillus oryzae on Japanese sake brewing. Journal of Bioscience and Bioengineering, 110(6), 679 - 683. Doi: 10.1016/j.jbiosc.2010.07.015.

Sivaramanan, S. (2014). Isolation of Cellulolytic Fungi and their Degradation on Cellulosic Agricultural Wastes. Journal of Academia and Industrial Research (JAIR), 2(8), 458 - 463. DOI:10.13140/2.1.3633.4080.

Sociedad Española de Microbiología. (2014). Clave dicotómica para la identificación de hongos aislados sistemáticamente en ambientes mediterráneos. Revista Semáforo, número 57. https://www.semicrobiologia.org/storage/secciones/publicaciones/ semaforo/57/articulos/30_Clave.pdf

Vázquez-Montoya, E.L., Castro-Ochoa, L.D., Maldonado-Mendoza, I.E., Luna-Suárez, S. y Castro-Martínez, C. (2020). Moringa straw as cellulase production inducer and cellulolytic fungi source. Rev. Argent. Microbiol., 52(1), 4 - 12. DOI: 10.1016/j.ram.2019.02.005.

\section{CITAR COMO:}

Delgado Olivares, L. G., \& Salas Asencios, R. (2021). Producción de etanol por digestión de residuos lignocelulósicos debido a hongos del suelo agrícola de la ciudad de Lima. Puriq, 3(1), 165-174. https://doi.org/10.37073/puriq.3.1.148 